ИЗВЕСТИЯ АКАДЕМИИ НАУК ЭСТОНСКОИ ССР. ТОМ 30 ФИЗИКА * МАТЕМАТИКА, 1981, № 3

\title{
О ВЛИЯНИИ ТОЛЩИНЫ ПОРИСТОГО ПОКРЫТИЯ, ПОЛУЧЕННОГО ПЛАЗМЕННЫМ НАПЫЛЕНИЕМ ПОРОШКА, НА ТЕПЛООТДАЧУ ПРИ КИПЕНИИ ЖИДКОСТИ
}

\author{
(Представил И. Эпик)
}

B $\left[{ }^{1,2}\right]$ отмечалось, что зависимость интенсивности теплоотдачи от толщины пористого покрытия при кипении на нем жидкости носит экстремальный характер. В настоящей статье этот вопрос рассматривается более подробно применительно к покрытиям, полученным плазменным напылением алюминиевого порошка. Исследование проведено в целях интенсификации охлаждения силовых полупроводниковых приборов.

Модель теплоотдачи при кипении на идеализированном пористом покрытии была рассмотрена в $\left[{ }^{1}\right]$. Согласно этой модели, перепад температур между поверхностью нагрева под пористым слоем и кипящей жидкостью $\Delta T$ состоит из трех компонентов

$$
\Delta T=\Delta T_{1}+\Delta T_{2}+\Delta T_{3},
$$

где $\Delta T_{1}-$ разность температур между поверхностью нагрева и паром в пористом материале

$$
\Delta T_{\mathrm{f}}=\frac{q}{\lambda_{3} m A} \frac{1+n \text {th }[m(L-\Delta L)]}{n+\operatorname{th}[m(L-\Delta L)]} ;
$$

$\Delta T_{2}$ - разность температур между паром в пористом материале и кипящей жидкостью в большом объеме

$$
\Delta T_{2}=q T^{\prime \prime} \mu(L-\Delta L) / r^{2} \mathrm{Q}^{2} k
$$

$\Delta T_{3}$ - разность температур на участке сухого пористого слоя

$$
\Delta T_{3}=q \Delta L / \lambda_{\mathrm{c}}
$$

В формулах (2)-(4) $q-$ тепловая нагрузка; $m=\sqrt{\alpha_{ж} U / \lambda_{\curvearrowright} A}-$ характеристика пористого слоя; $n=\alpha_{0} / \lambda_{2} m-$ характеристика внешней поверхности покрытия; $\alpha_{ж}=\lambda_{\text {ж }} / \delta$ и $\alpha_{0}-$ коэффициенты теплоотдачи при испарении микрослоя жидкости и на внешней поверхности пористого слоя соответственно; $\lambda_{\text {ж}}, \lambda_{\mathrm{c}}$ и $\lambda_{3}$ - коэффициенты теплопроводности жидкости, сухого и насыщенного жидкостью пористого материала соответственно; $U$ - периметр поверхности испарения; $A=1-\varepsilon-$ суммарная площадь сечения скелета покрытия и заполненных жидкостью пор; $\varepsilon$ - относительный объем пара в пористом материале; $\delta$ - толщина микрослоя жидкости на стенках паровых пор; $L$ - толщина покрытия; $\Delta L=L\left(1-q^{*} / q\right)$ - толщина сухого участка порис- 

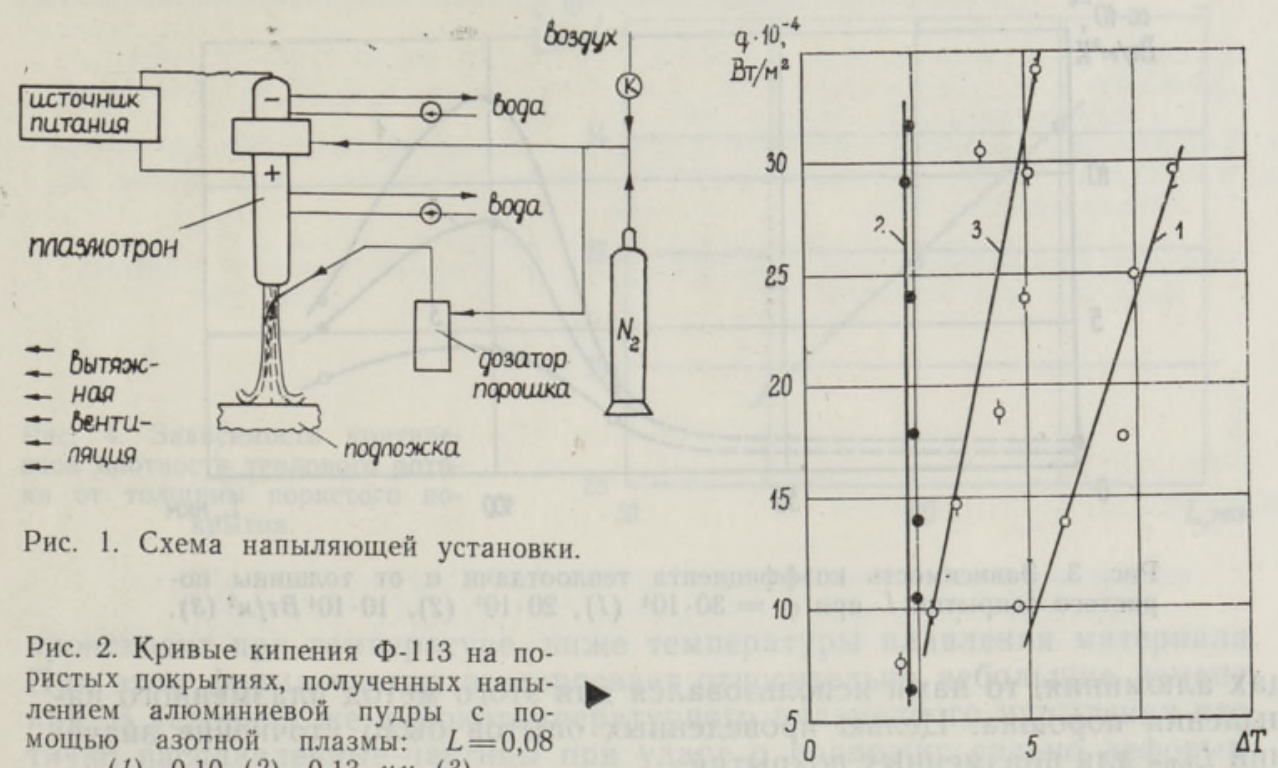

Рис. 1. Схема напыляющей установки.

Рис. 2. Кривые кипения Ф-113 на пористых покрытиях, полученных напылением алюминиевой пудры с помощью азотной плазмы: $L=0,08$ (1), 0,10 (2), 0,13 мм (3).

того слоя; $q^{*}$ - плотность теплового потока, при котором наступает внутрислойный кризис, т. е. начинается осушение покрытия; $T^{\prime \prime}$ - температура насыщения; $r$ - скрытая теплота парообразования; $\mu$ и @ - коэффициент динамической вязкости и плотность пара соответственно; $k$ - проницаемость покрытия для пара.

По сравнению с формулами в [ $\left.{ }^{1}\right]$ формулы (2) и (3) более точны. Они учитывают уменьшение рабочей толщины пористого покрытия при тепловых нагрузках $q>q^{*}$, при которых осушается часть пористого слоя $\Delta L$, а также влияние влажности пористого материала на процесс теплоотдачи.

Формулы (1) - (4) позволяют анализировать влияние толщины покрытия на интенсивность теплоотдачи при кипении жидкости. Составляющая $\Delta T_{1}$ в значительной мере зависит от величины эффективной теплоотдающей поверхности: она резко возрастает, когда толщина покрытия становится тоньше определенного предела, а при больших толщинах покрытия изменяется мало, так как $m(L-\Delta L) \gg 2$. В результате зависимость (2) упрощается

$$
\Delta T_{1}=q / \lambda_{a} m A \text {. }
$$

$\Delta T_{2}$ растет линейно с ростом толщины покрытия до начала внутрислойного кризиса. При дальнейшем утолщении покрытия $\Delta T_{2}$ остается постоянной и добавляется составляющая перегрева $\Delta T_{3}$.

Результирующая кривая $\alpha=q / \Delta T=f(L)$ имеет максимум, абсцисса

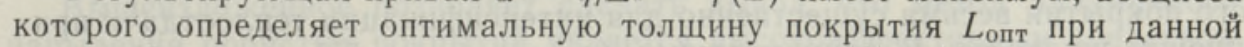
тепловой нагрузке. На основе анализа формул (1)-(4) можно заключить, что $L_{\text {опт }}$ уменьшается с ростом плотности теплового потока $q$, а также с уменьшением теплопроводности покрытия $\lambda_{z}$ и радиуса пор. Зависимость $L_{\text {опт }}$ от пористости является обычно экстремальной.

При кипении фреона Ф-113 на пористом медном покрытин, изготовленном методом порошковой металлургии, значения $L_{\text {опт }}$ составляли в зависимости от тепловой нагрузки $0,3-0,6$ мм [ $\left.{ }^{1}\right]$. Поскольку получение пористых алюминиевых покрытий методом порошковой металлургии связано с большими трудностями из-за наличия пленки $\mathrm{Al}_{2} \mathrm{O}_{3}$ на части- 


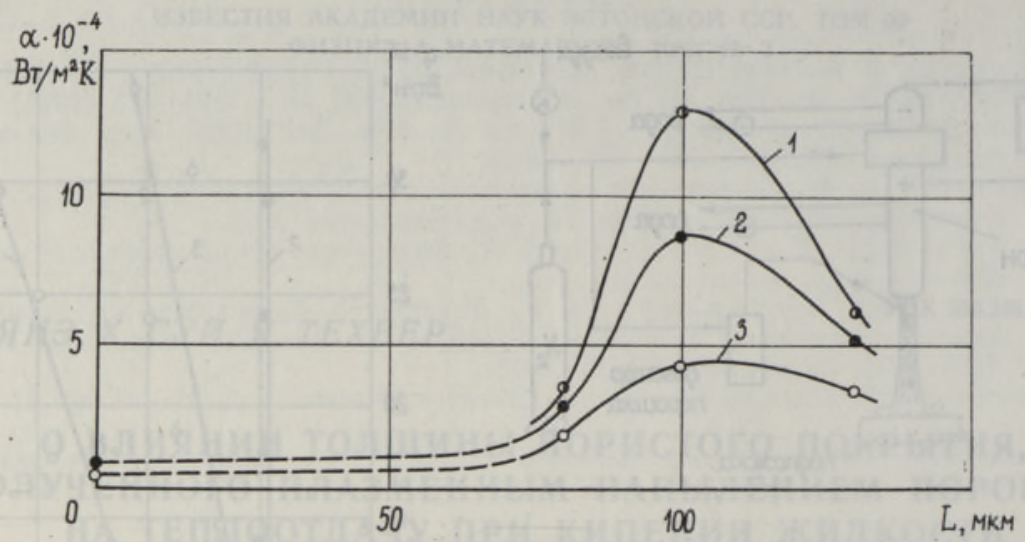

Рис. 3. Зависимость коэффициента теплоотдачи $\alpha$ от толщины пористого покрытия $L$ при $q=30 \cdot 10^{4}(1), 20 \cdot 10^{4}(2), 10 \cdot 10^{4} B r / M^{2}(3)$.

цах алюминия, то нами использовался для этого метод плазменного напыления порошка. Целью проведенных опытов было уточнение значе-

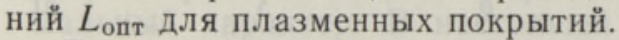

Схема напыляющей установки показана на рис. 1. Напыление покрытий осуществлялось плазменной струей, генерируемой дуговым плазмотроном постоянного тока с вихревой стабилизацией дуги. Потребляемая плазмотроном мощность составляла $7-10 \kappa B T$, в качестве рабочих газов использовали воздух или азот. Рассчитанная из энергетического баланса среднемассовая температура газа на выходе из плазмотрона изменялась в широких пределах до 3000 К. Напыляемым материалом служил алюминиевый порошок АПВ с размером частиц менее 63 мкм и полифракционная алюминиевая пудра ПАП-1. Подача пыли производилась по принципу пневмотранспорта. Материал распылялся на вращающиеся торцевые поверхности алюминиевых цилиндрических образцов диаметром 22 мм, после чего определялись теплообменные характеристики покрытий при кипении в специальной установке, аналогичной $\left[{ }^{3}\right]$.

Вышеизложенным способом были получены пористые алюминиевые покрытия с различной толщиной и пористостью (до $50 \%$ ), позволившие существенно интенсифицировать теплоотдачу при кипении жидкости. Характерные для этих покрытий кривые кипения фреона Ф-113, полученные при возрастании теплового потока, показаны на рис. 2. Использование восходящей ветви кривой кипения обусловлено необходимостью иметь гарантированный уровень теплосъема, так как кривые кипения при уменьшении теплового потока обычно располагаются левее представленных кривых.

Из рис. 2 и 3 следует, что определение оптимальной толщины пористого покрытия весьма существенно для интенсификации теплоотдачи при кипении жидкости. В данном случае (в отличие от $\left[{ }^{1}\right]$, где анализировались покрытия из меди) наблюдались гораздо меньшие значения $L_{\text {опт }}(0,09-0,12$ м. $)$ и значительно бо́льшие максимальные значения коэффициентов теплоотдачи $\alpha$, хотя использованный нами алюминий является, как известно, худшим по сравнению с медью проводником тепла. Эти различия в процессах теплоотдачи обусловлены особенностями внутренней структуры пористых покрытий, полученных методом порошковой металлургии и методом плазменного напыления. Известно $\left[{ }^{4}\right]$, что спекание частиц порошка методом порошковой металлургии 
Рис. 4. Зависимость критической плотности теплового потока от толщины пористого покрытия.

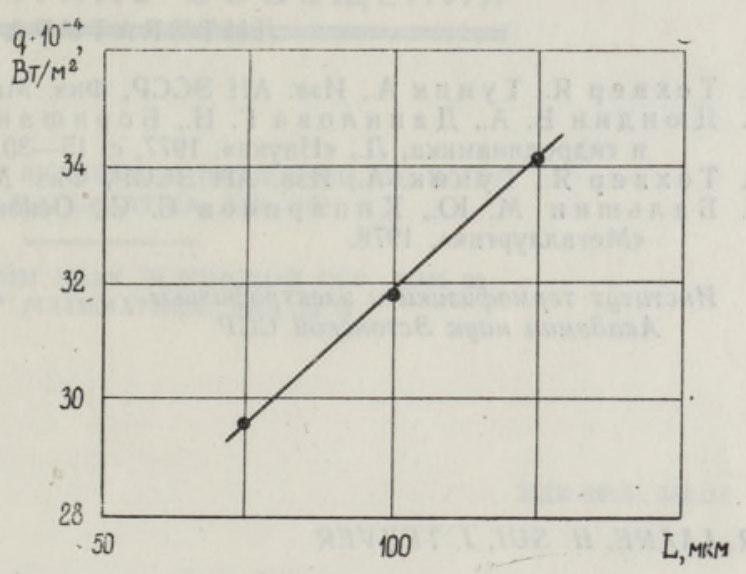

происходит при температуре, ниже температуры плавления материала. При этом форма частиц претерпевает относительно небольшие изменения. В условиях же высокотемпературного плазменного напыления частично расплавленные частицы при ударе о подложку сильно деформируются и спекаются, образуя систему пор с более сложной конфигурацией и с более меняющимся по длине порового канала живым сечением.

Неравномерность пористой структуры плазменных покрытий прослеживается и по толщине покрытия. Анализ микрошлифов показал, что эти покрытия можно условно разделить на два слоя - верхний шероховатый с толщиной, сравнимой со средним размером напыленных частиц, и нижний пористый. Структура верхнего слоя существенно отличается от структуры нижнего наличием крупных, расширяющихся к наружной поверхности пор.

Таким образом, значительное изменение размера живого сечения пор в покрытиях, полученных плазменным напылением порошка, приводит, с одной стороны, к резкому увеличению площади теплоотдающей поверхности, а с другой - к снижению проницаемости покрытия. В соответствии с этим в формуле (1) доля составляющей $\Delta T_{1}$ уменьшается, а доли составляющих $\Delta T_{2}$ и $\Delta T_{3}$ возрастают. Все это указывает на возможность значительно изменить оптимальную толщину плазменных покрытий в сторону их меньших значений.

Согласно рис. 4, толщина покрытия имеет весьма важное значение и с точки зрения возникновения кризиса кипения, так как от нее зависит влияющая на кризис теплоотдачи температура наружной, обращенной к большому объему жидкости поверхности покрытия. При $L<L_{\text {опт }}$ пористая поверхность перегревается относительно кипящей жидкости,

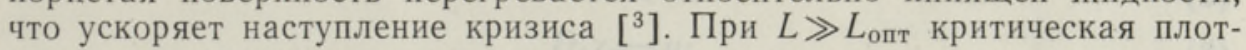
ность теплового потока практически не зависит от толщины покрытия.

Вышеизложенное позволяет сделать вывод, что метод плазменного напыления пористых покрытий является высокоэффективным средством интенсификации теплоотдачи при кипении жидкости. Образование пор с сильно меняющимся живым сечением позволяет резко уменьшить оптимальную толщину этих покрытий, а это в ряде практических случаев имеет весьма важное значение. 
Л И Т Е Р А Т У Р А

1. Техвер Я., Т уник А., Изв. АН ЭССР, Физ. Матем., 28, № 1, 68-72 (1979).

2. Дюндин В. А., Данил ова Г. Н., Боришанская А. В., В кн.: Теплообмен и гидродинамика, Л., «Наука», 1977, с. 15-30.

3. Техвер Я., Туник А., Изв. АН ЭССР, Физ. Матем., 26, № 2, 194-198 (1977).

4. Б а льш и н $M$. Ю., К и п а и сов С. С., Основы порошковой металлургии, M., «Металлургия», 1978.
Институт термофизики и электрофизики Академии наук Эстонской ССР
Поступила в редакцию
$6 /$ II 1981

\author{
R. LAANE, H. SUI, J. TEHVER
}

\title{
PLASMAPINDAMISMEETODIGA SAADUD POORSETE PINNAKATETE PAKSUSE MÕJU SOOJUSOLEKANDELE VEDELIKU KEEMISEL
}

Eksperimentaalselt ja täpsustatud teoreetilise mudeli põhjal on analüüsitud plasmajoaga pinnale kantud poorsete alumiiniumkatete paksuse mõju soojusülekandele freooni keemisel. Teiste meetoditega võrreldes saadakse plasmapindamisel ebaühtlasema elavristlõikega poorid, mis võimaldab peeneteralise tolmu $(<63 \mu \mathrm{m})$ korral vähendada kattekihi optimaalset paksust $0,09-0,12$ millimeetrini.

\section{INFLUENCE OF THE THICKNESS OF POROUS PLASMA SPRAYED COATINGS ON HEAT TRANSFER FOR A BOILING FLUID}

The influence of the thickness of porous coatings on heat transfer processes for boiling freon F-113 is analyzed on the basis of a refined theoretical model and experimental data. The porous coatings were obtained by spraying fine aluminum powder $(<63 \mu \mathrm{m})$ on a surface with the aid of a plasma jet generated in an arc plasmotron.

Significant increase in non-uniformity of cross sections of pores and the improvement of porous structure can be observed in coatings produced by plasma spraying. Therefore the optimum (from the viewpoint of heat transfer intensifying) thickness of coatings can be decreased up to $0.09-0.12 \mathrm{~mm}$. Compared to other methods of porous coating, the values of heat transfer coefficient increase essentially.

The obtained results permit to intensify evaporative cooling of heat-generating elements by the use of porous coatings with optimum thickness. 